\title{
The benefit of curative liver resection with a selective bile duct preserving approach for hepatocellular carcinoma with macroscopic bile duct tumor thrombus
}

\author{
Anon Chotirosniramit, Akkaphod Liwattanakun, Sunhawit Junrungsee, Wasana Ko-iam, Trichak Sandhu, \\ Worakitti Lapisatepun \\ Division of Hepatobiliary and Pancreatic Surgery, Department of Surgery, Faculty of Medicine, Chiang Mai University Hospital, Chiang Mai, \\ Thailand \\ Contributions: (I) Conception and design: W Lapisatepun, S Junrungsee, T Sandhu, A Chotirosniramit; (II) Administrative support: W Ko-iam; (III) \\ Provision of study materials or patients: All authors; (IV) Collection and assembly of data: A Liwattanakun; (V) Data analysis and interpretation: \\ W Ko-iam, W Lapisatepun; (VI) Manuscript writing: All authors; (VII) Final approval of manuscript: All authors. \\ Correspondence to: Workitti Lapisatepun. Instructor at Department of Surgery, Faculty of Medicine, Chiang Mai University Hospital, Thailand. \\ Email: worakitti.1@cmu.ac.th.
}

\begin{abstract}
Background: Hepatocellular carcinoma (HCC) presenting with macroscopic bile duct tumor thrombus (BDTT) is an uncommon event. The role of a curative hepatic resection and associated long-term outcomes remain controversial. In addition the necessity for bile duct resection is still unclear. The aim of this study was to evaluate outcomes of hepatectomy with a selective bile duct preservation approach for HCC with BDTT in comparison to outcomes without BDTT.

Methods: A total of 22 HCC with BDTT patients who had undergone curative hepatic resection with a selective bile duct preservation approach at our institute were retrospectively reviewed. These were compared to group of $145 \mathrm{HCC}$ without BDTT patients. The impact of curative surgical resection and BDTT on clinical outcomes and survival after surgical resection were analyzed.

Results: All HCC with BDTT cases underwent major hepatectomy vs. 32.4\% in the comparative group. Bile duct preservation rate was $56.5 \%$. The 1-, 3- and 5-year survival rates of HCC with BDTT patients in comparison to the HCC without BDTT group were $81.8 \%, 52.8 \%$ and $52.8 \%$ vs. $73.6 \%, 55.6 \%$ and $40.7 \%$ $(\mathrm{P}=0.804)$ respectively. Positive resection margin, tumor size $\geq 5 \mathrm{~cm}$ and $\mathrm{AFP} \geq 200 \mathrm{IU} / \mathrm{mL}$ were significant risk factors regarding overall survival. However, it is unclear whether presence of a bile duct tumor thrombus has an adverse impact on either recurrence free survival or overall survival.

Conclusions: Bile duct obstruction from tumor thrombus did not necessarily indicate an advanced form of disease. Tumor size and AFP had greater impact on long-term outcomes than bile duct tumor thrombus. Major liver resection with a selective bile duct preserving approach in HCC with BDTT can achieve favorable outcomes comparable to those of HCC without BDTT in selected patients.
\end{abstract}

Keywords: Hepatocellular carcinoma (HCC); bile duct tumor thrombus (BDTT); bile duct preserve; outcomes

Submitted Jul 22, 2019. Accepted for publication Oct 09, 2019.

doi: $10.21037 / \mathrm{hbsn} .2019 .10 .26$

View this article at: http://dx.doi.org/10.21037/hbsn.2019.10.26

\section{Introduction}

Hepatocellular carcinoma (HCC) was listed as the fifth most common cancer in males and the ninth in females globally (1). In Chiang Mai, Thailand, the incidence of
HCC was 33.6 in 100,000 males and 11.6 in 100,000 females (2). Regardless of the advancement of hepatic disease, the presentation of HCC with obstructive jaundice from bile duct tumor thrombus (BDTT) was relatively rare, 
the incidence ranging from $0.8-12.9 \%$ (3). The benefits of curative surgery in HCC patients with BDTT remained controversial. Several studies showed a higher recurrence rate and lower overall survival when compared with HCC without BDTT $(4,5)$. In addition HCC with BDTT may need more aggressive surgery, with or without bile duct resection, and consequently have a higher potential for postoperative complications as well as peri-operative mortality (6). To date, there is no standard surgical procedure for HCC with BDTT and the treatment strategy varies between centers.

This study aimed to analyze outcomes of curative resection with a selective bile duct preserving approach in patients with macroscopic BDTT compared with HCC without BDTT and to identify the risk factors which influence overall survival and recurrence free survival.

We present the following article in accordance with the STROBE reporting checklist (available at http://dx.doi. org/10.21037/hbsn.2019.10.26).

\section{Methods}

Between 2001 and 2016, 457 HCC patients underwent curative hepatic resection at our institute. All HCC cases were confirmed by histopathological report. In this study, $23 \mathrm{HCC}$ cases with macroscopic BDTT distal to $1^{\text {st }}$ order bile duct (type 2, 3 and 4 according to Ueda classification) were compared with 145 cases of HCC without BDTT who underwent curative resection from 2011 to 2015 (7).

All patients gave written consent for a review of their medical records. This study (study code: Sur-2557-02473) was approved by the institutional review board of Chiang Mai University (certificate of approval number 346/2014). Baseline characteristics of patients, perioperative data and histopathologic reports were retrospectively reviewed. All follow up data including postoperative imaging, time-torecurrence and overall survival were prospectively collected from electronic medical records. The study was performed in accordance with the Declaration of Helsinki (as revised in 2013).

\section{Preoperative assessment}

All patients who had been identified as having suspected HCC attended hepatobiliary and pancreatic surgery (HBP) clinic for evaluation for curative hepatic resection. In the majority of cases multiphase contrast enhanced computed tomography (CT) had been used for diagnosis.
Patients with renal insufficiency or where the diagnosis was uncertain from the CT scan underwent hepatocyte specific contrast magnetic resonance imaging (MRI). All preoperative imaging studies were interpreted by either HBP specialists or abdominal imaging specialized radiologists.

There was no facility for the indocyanine green retention test in our institution during that period of time, so preoperative liver preservation function and safety of hepatic resection were carefully evaluated by volumetric study, liver function test, Child-Pugh classification, coagulation profile and indirect signs of portal hypertension such as significant intra-abdominal porto-systemic shunt, splenomegaly, and thrombo-cytopenia. In cases involving hyperbilirubinemia pre-operative biliary drainage was selectively done in cases of severe cholangitis, severe malnutrition with hypoalbuminemia and marked hyperbilirubinemia (total bili-rubin $>10 \mathrm{mg} / \mathrm{dL}$ ). This practice was to limit the risk of tumor bleeding and seeding. Our preferred method for biliary drainage was percutaneous transhepatic biliary drainage (PTBD). Liver function was re-evaluated in patients who underwent pre-operative biliary drainage following the procedure. If the total bilirubin level failed to decrease or liver synthetic function remain abnormal, curative resection would be aborted due to the risk of postoperative liver failure. Pre-operative locoregional treatment for resectable cases was not used in resectable HCC with BDTT cases because locoregional treatment in patients with obstructive jaundice has been shown to have a greater chance of causing a worsening in liver function and may lead to liver failure.

\section{Selective bile duct preserving approach in HCC with BDTT}

All patients underwent major hepatectomy with the intention of preserving the bile duct. However a major hepatectomy with extrahepatic bile duct resection was considered in cases of extensive biliary thrombosis, failed tumor thrombectomy, tumor invasion of hepatic duct confluence and when it was not possible to exclude an intraductal type cholangiocarcinoma pre-operatively.

Intra operative ultrasound was used to identify occult metastasis in the contralateral side, extension of tumor thrombus into the bile duct and transection plain. Hepatectomy was carried out via the anterior approach with individual ligation of hepatic inflow (hepatic artery and portal vein). Parenchymal transection technique varied depending on surgeon preference. Parenchymal 
transection was done until the approach to the hilar when the ipsilateral hepatic duct was transected. The tumor thrombus was removed by either manually milking the bile duct or by balloon catheter thrombectomy via the hepatic duct stump. If the tumor thrombus could not be completely removed via the hepatic duct stump, a choledochotomy was done to facilitate complete removal. After tumor thrombectomy, a choledochoscopy was used to investigate the presence of any residual tumor. The choledochotomy was closed with PDS 4-0 interrupted with T-tube retention. Following this procedure, the parenchymal transection was continued; the hepatic vein was cut and over sewn with prolene 4-0 using a continuous technique. As a follow up for the tumor thrombectomy technique, if the tumor thrombus could not be easily removed by milking or balloon catheter thrombectomy, a bile duct resection with hepaticojejunostomy was carried out.

\section{Post-operative data and follow-up}

Post-operative complications were recorded and graded using the Clavien-Dindo classification. Following surgery, all patients were scheduled for an abdominal multiphase CT scan and chest X-ray every 3-4 months. There was no adjuvant treatment after curative resection regardless of pathologic report or staging. Disease free survival was recorded in electronic patient medical records. The date of the last follow up to determine overall survival was $16^{\text {th }}$ June 2017. Treatment of recurrence was determined by a multi-disciplinary team including a surgeon, oncologist, radiologist, and an interventional radiologist.

\section{Statistical analysis}

All data was collected prospectively from the hospital electronic database. A Chi-squared test was used to compare categorical data. A $t$-test or Mann-Whitney U-test was used to compare continuous data. The Kaplan-Meier method was used to analyze overall survival and recurrencefree survival. Survival curves from the two groups were compared by log-rank test. Univariate and Multivariate analysis were performed using Cox proportional hazard model. The significant risk factors from the univariate analysis were manually entered in the multivariate analysis to identify the most critical risk factors. A $\mathrm{P}$ value $<0.05$ was considered as statistically significant in all analyses. All data was analyzed using IBM SPSS Statistics 23.0.0 (IBM Corporations).

\section{Results}

\section{Baseline characteristics}

Patient profiles and perioperative data are described in Table 1. Twenty-three patients in the HCC with BDTT group and 145 patients in the HCC without BDTT underwent curative hepatic resection. Mean age at presentation was significantly lower in the BDTT group (50.8 \pm 9.9 vs. $55.7 \pm 11.2$ years, $\mathrm{P}=0.047$ ). Both groups were predominantly male $(87.0 \%$ vs. $73.1 \%, \mathrm{P}=0.154)$. Most patients were positive for chronic hepatitis $\mathrm{B}$ infection $78.3 \%$ vs. $68.9 \%(\mathrm{P}=0.772)$ and cirrhosis $65.2 \%$ vs. $75.7 \%$ $(\mathrm{P}=0.286)$. Mean preoperative albumin level was similar across both groups $(3.6 \pm 0.9$ vs. $3.6 \pm 0.6 \mathrm{~g} / \mathrm{dL}, \mathrm{P}=0.824)$. Median serum alpha-fetoprotein and CA 19-9 were higher in the BDTT group 182.8 vs. $25.4 \mathrm{ng} / \mathrm{mL}(\mathrm{P}=0.610)$ and 53.2 vs. $25.7 \mathrm{ng} / \mathrm{mL}(\mathrm{P}=0.002)$, respectively. Seventy percent of the HCC with BDTT group presented with jaundice, and the mean serum total bilirubin before surgery was $5.4 \mathrm{mg} / \mathrm{dL}$. Fifty-six percent of the HCC with BDTT group had had an episode of cholangitis before surgery. However, only $26 \%$ underwent the percutaneous transhepatic biliary drainage (PTBD) procedure. There was no significance difference in pre-operative characteristics between the HCC with BDTT group who underwent hepatectomy with extra-hepatic bile duct resection and those in the bile duct preservation group (Table S1).

\section{Operative data and postoperative complications}

This study included only patients who underwent curativeintent surgery. The incidence of major hepatectomy was significantly higher in the HCC with BDTT group (95.6\% vs. $35.2 \%, \mathrm{P}<0.001$ ). With the selective bile duct preserving approach, $34.8 \%$ of patients underwent a major hepatectomy alone and $21.7 \%$ of patients underwent major hepatectomy with tumor thrombectomy without bile duct resection. In $39.2 \%$ of cases a failed tumor thrombectomy necessitated an extended hepatectomy with bile duct resection (Table 2). One patient in the HCC with BDTT group underwent a palliative choledochotomy to remove a tumor thrombus with T-tube insertion due to contralateral hepatic lobe metastasis which was undetected from the preoperative imaging.

Operative time, blood loss, blood transfusion and overall postoperative complications were significantly higher in the BDTT group, $420.2 \pm 161.4$ vs. $224.93 \pm 85.1$ minutes $(\mathrm{P}<0.001) ; 1,200$ vs. $600 \mathrm{~mL}(\mathrm{P}=0.001) ; 43.5 \%$ vs. $22.8 \%$ 
Table 1 Baseline characteristics and operative data of the patients

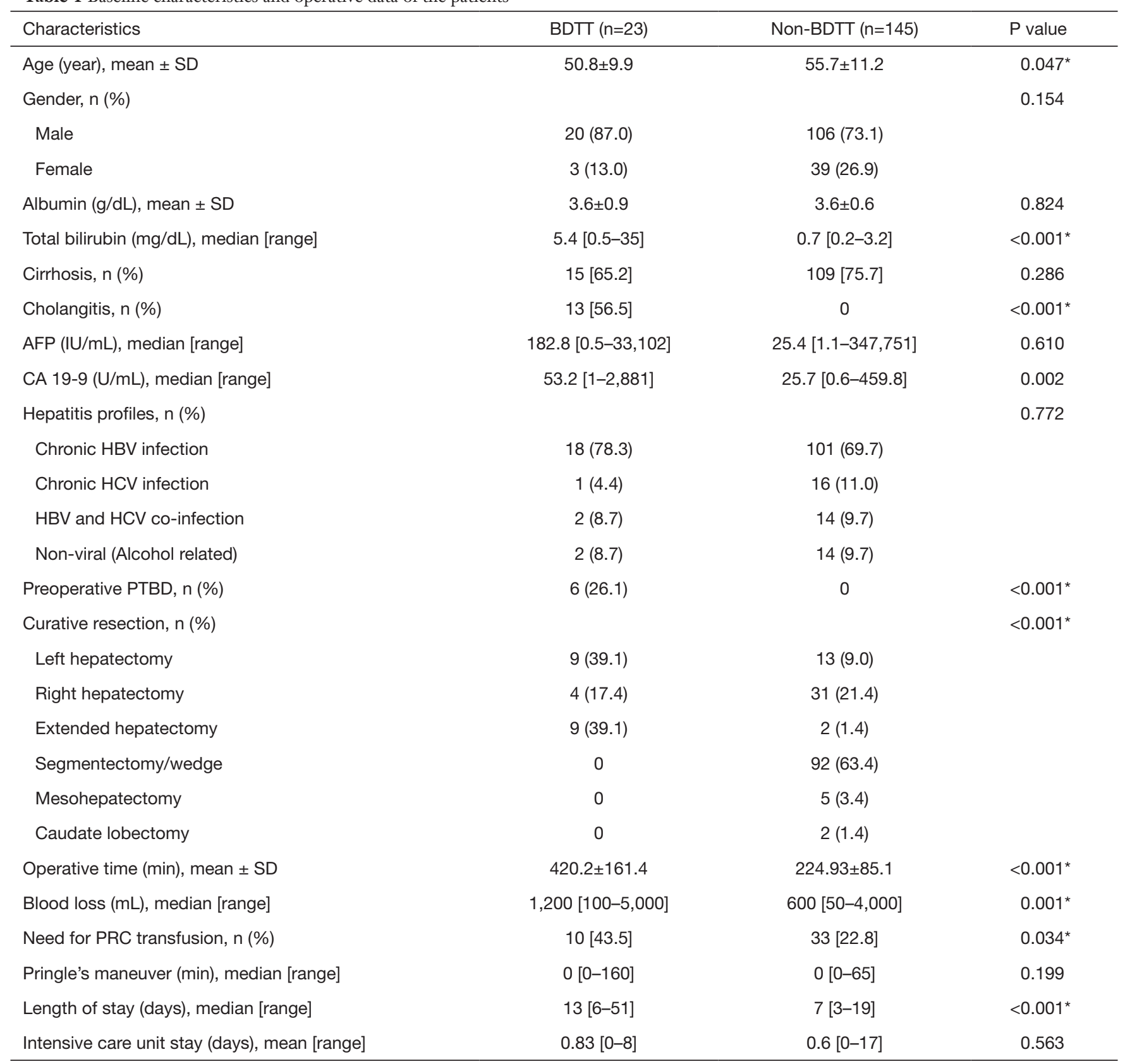

*, statistical significance. AFP, alpha-fetoprotein; CA 19-9, carbohydrate antigen 19-9; HBV, hepatitis B virus; HCV, hepatitis C virus; PTBD, percutaneous transhepatic biliary drainage; PRC, packed red cell.

( $\mathrm{P}=0.034)$; and $43.5 \%$ vs. $19.6 \%(\mathrm{P}=0.006)$, respectively. Mean length of hospital stay was significantly higher in the BDTT group, 13 vs. 7 days $(\mathrm{P}<0.001)$. Two patients $(8.7 \%)$, in the BDTT group died within 30 days postoperative. The first patient died after a palliative procedure to remove a tumor thrombus. The cause of death was postoperative cholangitis with septic shock. The second patient underwent an extended left hepatectomy with a bile duct resection complicated by an iatrogenic right hepatic vein injury. Even though it was possible for this to be reconstructed intraoperatively, unfortunately, the patient had a right hepatic vein thrombosis complicated by postoperative liver failure. There were no peri-operative deaths in the HCC without BDTT group. In the subgroup analysis, patients 
Table 2 Extent of surgical procedure for HCC patients with BDTT $(\mathrm{n}=23)$

\begin{tabular}{lc}
\hline Procedures & Frequency (\%) \\
\hline Left hepatectomy & $5(21.7)$ \\
Left hepatectomy with tumor thrombectomy & $4(17.4)$ \\
Right hepatectomy & $3(13.1)$ \\
Right hepatectomy with tumor thrombectomy & $1(4.3)$ \\
Extended hepatectomy with bile duct resection & $9(39.1)$ \\
Removal of bile duct tumor thrombus only & $1(4.3)$ \\
\hline
\end{tabular}

HCC, hepatocellular carcinoma; BDTT, bile duct tumor thrombus.

in the HCC with BDTT group who underwent bile duct resection had a significantly longer operative time $(\mathrm{P}=0.011)$. However, there was no significant difference in blood loss, post-operative complications and 30-day mortality between the two groups (Table S1).

\section{Histopathologic reports}

Histopathologic reports are described in Table 3. Median tumor size was slightly larger in the BDTT group, $5.5 \mathrm{vs.}$ $5.0 \mathrm{~cm}$, but this was not statistically significant $(\mathrm{P}=0.516)$. There was a tendency for patients in the HCC with BDTT group to have more venous and lymphatic/neural invasion, 90.5\% vs. $73.8 \%(\mathrm{P}=0.095)$ and $14.3 \%$ vs. $11.0 \%(\mathrm{P}=0.662)$, respectively, again these were not significant. TNM staging was not significantly different between groups and the majority of patients were at stage II according to the AJCC $8^{\text {th }}$ edition criteria. R1 resection was defined as having a margin status of less than $1 \mathrm{~mm}$. Rate of $\mathrm{R} 1$ resection was higher in the BDTT group, 28.6\% vs. $18.6 \%(\mathrm{P}=0.286)$. In the subgroup analysis, there was no significant difference in terms of staging and resection margin status between the bile duct resection and bile duct preservation group (Table S1).

\section{Long term survival and treatment of recurrence}

The patient who underwent a palliative removal of tumor thrombus procedure was excluded from the survival analysis $(\mathrm{n}=1)$. Median overall survival and time to recurrence of all HCC patients who underwent curative resection was 46 and 10 months respectively. Median overall survival and time to recurrence for the BDTT group $v s$. non-BDTT group were 80 vs. 44 months and 9 vs. 10 months, respectively. The 1-, 3- and 5-year overall survival rates
Table 3 Histopathological data and post-operative outcomes of patients

\begin{tabular}{|c|c|c|c|}
\hline Variables & $\begin{array}{l}\text { BDTT } \\
(n=23)\end{array}$ & $\begin{array}{c}\text { Non-BDTT } \\
(\mathrm{n}=145)\end{array}$ & $P$ value \\
\hline Number of $\mathrm{HCC}$, median [range] & $1[1-3]$ & $1[1-6]$ & 0.656 \\
\hline $\begin{array}{l}\text { Largest tumor diameter }(\mathrm{cm}) \text {, } \\
\text { median [range] }\end{array}$ & $5.5[2-19]$ & $5[0.8-20]$ & 0.516 \\
\hline Margin <1 mm, n (\%) & $6(28.6)$ & $27(18.6)$ & 0.286 \\
\hline Venous invasion, $\mathrm{n}(\%)$ & 19 (90.5) & $107(73.8)$ & 0.095 \\
\hline Lymphatic/neural invasion, n (\%) & $3(14.3)$ & $16(11.0)$ & 0.662 \\
\hline AJCC $8^{\text {th }}$ staging & & & 0.456 \\
\hline IA & $9(6.2)$ & $1(4.5)$ & \\
\hline IB & $26(17.9)$ & $2(9.1)$ & \\
\hline II & $86(59.3)$ & $16(72.7)$ & \\
\hline IIIA & $13(9.0)$ & $3(3.6)$ & \\
\hline IIIB & $11(7.6)$ & $0(0)$ & \\
\hline $\begin{array}{l}\text { Postoperative complication } \\
\text { (Clavien-Dindo grade), n (\%) }\end{array}$ & & & $0.008^{*}$ \\
\hline No complications & $13(56.5)$ & $118(81.4)$ & \\
\hline Grade I & $2(8.7)$ & $5(3.6)$ & \\
\hline Grade II & $4(17.4)$ & $11(7.2)$ & \\
\hline Grade IIla & $1(4.4)$ & $5(3.4)$ & \\
\hline Grade IVa & $3(13)$ & $6(4.1)$ & \\
\hline 30-day mortality, n (\%) & $2(8.7)$ & 0 & $0.028^{*}$ \\
\hline Pattern of recurrence, $\mathrm{n}(\%)$ & & & 0.126 \\
\hline Intrahepatic recurrence & $5(38.5)$ & $36(64.3)$ & \\
\hline Intraductal recurrence & 0 & 0 & \\
\hline Lymph node metastasis & 0 & 0 & \\
\hline Pulmonary metastasis & $2(15.4)$ & $3(5.4)$ & \\
\hline Peritoneal metastasis & $1(7.7)$ & 0 & \\
\hline Combined metastasis & $5(38.5)$ & $17(15.6)$ & \\
\hline Treatment after recurrence, $\mathrm{n}(\%)$ & & & 0.499 \\
\hline Re-resection/metastectomy & $1(8.3)$ & $1(2.1)$ & \\
\hline TACE & $5(41.7)$ & $28(59.6)$ & \\
\hline DEl/RFA & 0 & $1(2.1)$ & \\
\hline Sorafenib & $1(8.3)$ & $5(10.6)$ & \\
\hline Combined treatment & $5(41.7)$ & $12(25.5)$ & \\
\hline
\end{tabular}

*, statistical significance. HCC, hepatocellular carcinoma; TACE, transarterial chemoembolization; DEI, direct ethanol injection; RFA, radiofrequency ablation. 

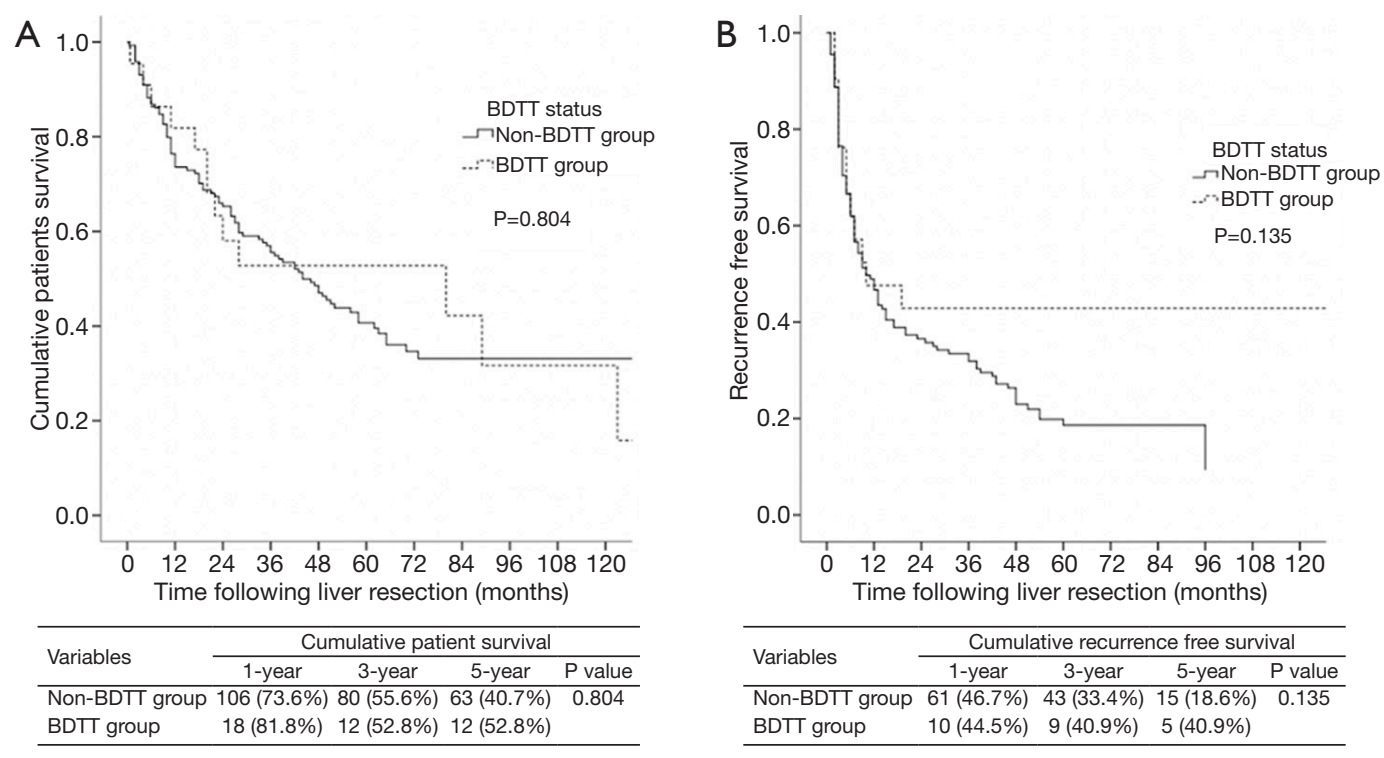

Figure 1 (A) Kaplan-Meier overall survival analysis and (B) Kaplan-Meier recurrence free survival analysis showing comparison between BDTT and non-BDTT group. BDTT, bile duct tumor thrombus.
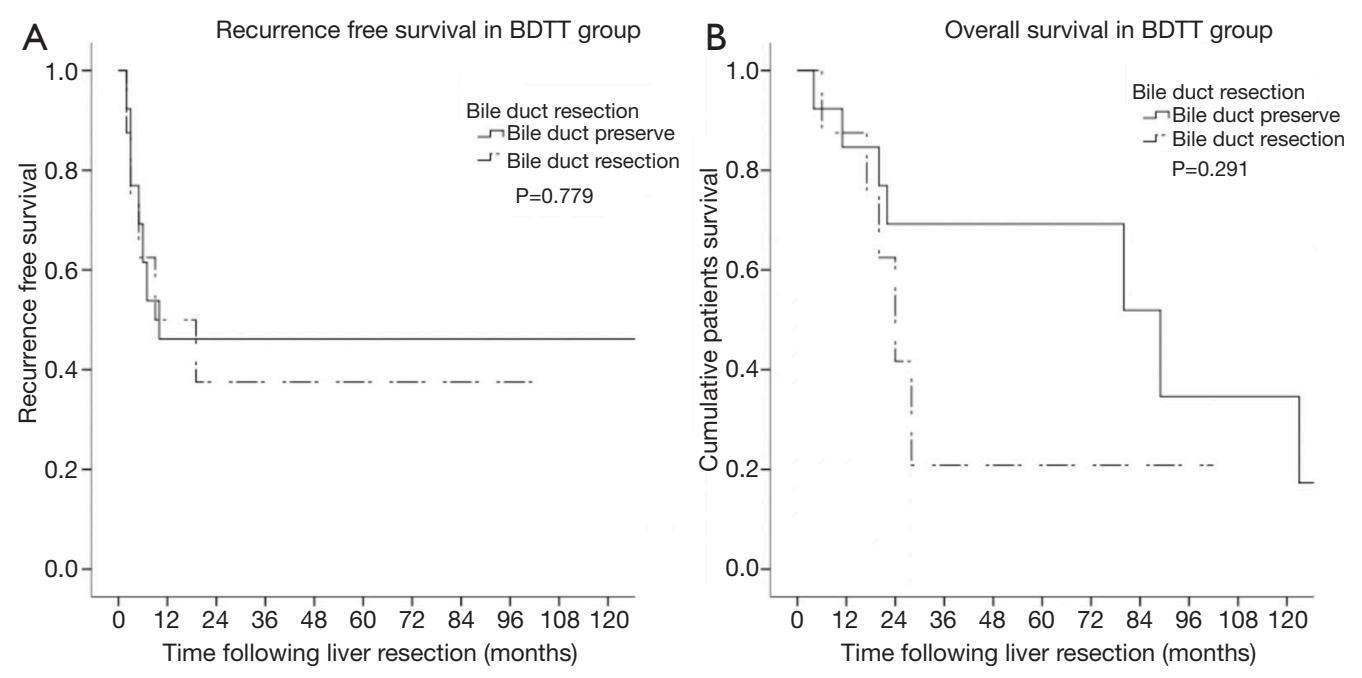

Figure 2 (A) Kaplan-Meier overall survival analysis and (B) Kaplan-Meier recurrence free survival analysis showing comparison between bile duct preserve and bile duct resection in BDTT group. BDTT, bile duct tumor thrombus.

in BDTT group were $81.8 \%, 52.8 \%$ and $52.8 \%$ in comparison to the non-BDTT group which were $73.6 \%$, $55.6 \%$ and $40.7 \%$, respectively $(\mathrm{P}$ value $=0.804)$. The $1-$, 3 - and 5-year recurrence free survival rates were $44.51 \%$, $40.9 \%$ and $40.9 \%$, the non-BDTT group being $46.7 \%$, $33.4 \%$ and $18.6 \%$, respectively $(\mathrm{P}$ value $=0.135)$ (Figure 1$)$. As regards the selective bile duct preservation approach in the HCC with BDTT group, long-term overall survival and recurrence free survival were not significantly different between the bile duct preservation and bile duct resection groups ( $\mathrm{P}$ value $=0.779$ and 0.291 ) (Figure 2).

Pattern and treatment of recurrence are shown in Table 3. The most common recurrence was intrahepatic metastasis [38.5\% vs. $64.3 \%$ (BDTT vs. non-BDTT)]. The most common extrahepatic metastasis site were the lungs [15.4\% vs. 5.4\% (BDTT vs. non-BDTT)]. There 
Table 4 Analysis of recurrence free survival and overall survival using Cox proportional hazard regression model ( $\mathrm{n}=167)$

\begin{tabular}{|c|c|c|c|c|c|c|c|c|}
\hline \multirow{2}{*}{ Prognostic factors } & \multicolumn{4}{|c|}{ Recurrence free survival } & \multicolumn{4}{|c|}{ Overall survival } \\
\hline & $\mathrm{HR}(95 \% \mathrm{Cl})$ & $P$ value & $\mathrm{HR}(95 \% \mathrm{Cl})$ & $P$ value & $\mathrm{HR}(95 \% \mathrm{Cl})$ & $P$ value & $\mathrm{HR}(95 \% \mathrm{Cl})$ & $P$ value \\
\hline \multicolumn{9}{|l|}{ Peri-operative factors } \\
\hline Bile duct tumor thrombus & $0.70(0.39-1.24)$ & 0.221 & & & $0.93(0.52-1.67)$ & 0.805 & & \\
\hline AFP $\geq 200 \mathrm{IU} / \mathrm{mL}$ & $1.47(1.01-2.14)$ & $0.045^{*}$ & $1.08(0.73-1.62)$ & 0.700 & $2.11(1.42-3.15)$ & $<0.001^{*}$ & $1.57(1.03-2.41)$ & $0.037^{\star}$ \\
\hline Age $\geq 60$ years & $0.85(0.56-1.30)$ & 0.458 & & & $0.84(0.54-1.30)$ & 0.437 & & \\
\hline Blood loss >1,000 mL & $1.34(0.87-2.05)$ & 0.181 & & & $1.72(1.12-2.65)$ & $0.013^{*}$ & $0.88(0.48-1.61)$ & 0.672 \\
\hline Blood transfusion & $1.79(0.77-1.81)$ & 0.465 & & & $1.68(1.09-2.59)$ & $0.019^{*}$ & $1.13(0.59-2.09)$ & 0.739 \\
\hline Multiple tumors & $1.87(0.77-1.82)$ & 0.437 & & & $0.89(0.54-1.47)$ & 0.648 & & \\
\hline R1 margin & $1.98(1.29-3.03)$ & $0.002^{*}$ & $1.65(1.06-2.57)$ & $0.028^{\star}$ & $2.05(1.31-3.21)$ & $0.002^{*}$ & $1.50(0.93-2.42)$ & 0.095 \\
\hline Venous invasion & $1.67(1.08-2.65)$ & $0.020^{\star}$ & $1.28(0.82-2.01)$ & 0.279 & $2.60(1.48-4.57)$ & $0.001^{*}$ & $1.79(0.99-3.20)$ & 0.055 \\
\hline Lymphatic/neural invasion & $1.96(0.18-3.25)$ & $0.010^{*}$ & $1.58(0.93-2.69)$ & 0.090 & $2.11(1.23-3.61)$ & $0.007^{*}$ & $1.71(0.97-3.04)$ & 0.063 \\
\hline Cirrhosis/fibrosis & $1.19(0.77-1.83)$ & 0.467 & & & $1.23(0.78-1.94)$ & 0.370 & & \\
\hline
\end{tabular}

*, statistical significance. AFP, alpha-fetoprotein; R1 margin, surgical margin $<1 \mathrm{~mm}$.

was no recurrence in the biliary tract in this sample. The most common treatment of recurrence was trans-arterial chemoembolization (TACE) $[41.7 \%$ vs. $59.6 \%$ (BDTT vs. non-BDTT)]. Two cases developed a post-TACE liver abscess in the BDTT group and both of them had bilioenteric anastomosis. The pattern and treatment of recurrence were not statistically difference between the groups ( $\mathrm{P}$ values $=0.126$ and 0.499 ).

\section{Risk factor analysis for overall survival and recurrence free survival}

Univariate and multivariate Cox proportional regression analysis were used to identify risk factors for overall survival and recurrence free survival as shown in Table 4. Presence of a BDTT did not have an adverse im-pact on either recurrence free survival or overall survival $[\mathrm{HR}=0.70(0.39-1.24)$, $\mathrm{P}=0.221$ and $\mathrm{HR}=0.93$ (0.52-1.67), $\mathrm{P}=0.805]$, respectively. From the multivariate analysis, tumor size $\geq 5 \mathrm{~cm}$ and positive resection margin were significant risk factors for recurrence. Tumor size $\geq 5 \mathrm{~cm}$ and AFP $\geq 200 \mathrm{IU} / \mathrm{mL}$ were significant risk factors for overall survival.

\section{Discussion}

Over this 15-year period the number of patients with HCC with macroscopic BDTT who underwent curative resection numbered 23 out of a total of 457 HCC-patients. The incidence of BDTT was $5.03 \%$ which falls within the range described in other studies of $1.2-12.9 \%(4,8)$. The hepatitis $B$ virus is endemic in Thailand and the majority of patients were positive for chronic hepatitis B infection (9). In addition, at the time this data was recorded the ultrasound-screening program in Thailand was not widely established so many patients in the early stages of HCC would not be detected. This meant that half of the patients in our sample presented with an HCC greater than $5 \mathrm{~cm}$ which is relatively large in comparison to other studies (10-12).

As seen in most other studies, curative hepatic resection for HCC with BDTT required a major hepatectomy. However, the management of tumor thrombus and bile duct issues is still controversial and varies between centers 


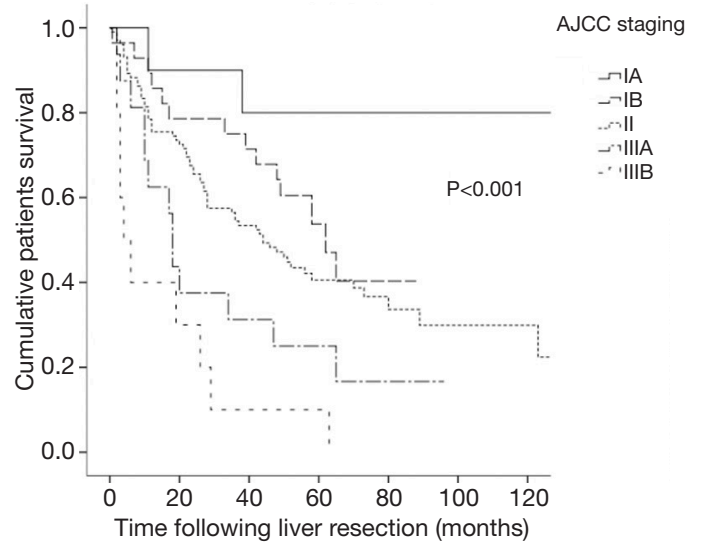

Figure 3 Kaplan-Meier overall survival analysis showing comparison between AJCC $8^{\text {th }}$ staging.

$(3,5,13,14)$. A hypothesis in a study by Zeng et al. was based on histopathologic findings that in HCC patients with BDTT the tumor invaded the submucosa then disseminated along the biliary tree. However, the length of submucosa that was invaded and infiltrated by the tumor was not clear (11). The multicenter trial by Moon et al. did not demonstrate the benefits of bile duct resection as an independent factor to improve overall survival (3). In 2015, Yamamoto et al. proposed bile duct preserving surgery for HCC with BDTT called a peeling-technique (14). However, there were several reports of recurrence of BDTT without a primary tumor after hepatic resection with tumor thrombectomy $(15,16)$. A more recent multi-center study by Kim et al. showed significant superior overall survival in a combined-bile duct resection group (17).

With regard to the selective bile duct preserving approach, the long-term outcome was not found to be significantly different from the BDTT with bile duct resection group. The long-term overall survival and recurrence free survival in HCC with BDTT patients was comparable to several recent studies $(16,18,19)$. Interestingly, there was no recurrence of BDTT in our series. According to AJCC $8^{\text {th }}$ edition for HCC staging, there is no significant difference in staging between each group in our study (both the non-BDTT $v s$. BDTT group and the Bile duct resection $v s$. Bile duct preservation for BDTT group). In addition, as reported in another publication, overall survival among resectable HCC patients was significantly predicted by AJCC $8^{\text {th }}$ staging criteria rather than by presence of BDTT (Figure 3) (20).

From a surgical point of view, as in another studies, more aggressive and complex surgery in the BDTT group rather inevitably caused significantly higher postoperative complications and mortality rates $(17,21)$.

With regard to tumor factors, presence of BDTT did not show a statistically significant influence on both overall and recurrence free survival. In our study, the histopathologic data indicated that in more than $50 \%$ of cases in which the tumors were larger than $5 \mathrm{~cm}$ and in nearly $80 \%$ where there was evidence of venous invasion there was a poorer overall survival and more frequent recurrence rate.

The most common site of recurrence was intrahepatic metastasis, usually treated by TACE or ablation. However either TACE or ablation in patients who have pre-existing bilioenteric anastomosis may cause complications regarding liver abscesses after the procedure $(22,23)$. Finally, the bile duct preservation strategy may confer benefits regarding the future choice of treatment in a high recurrence rate disease as HCC without compromising the long-term outcomes.

The limitation of this study was the small number of patients in both groups from a single center. However, the data collected warrant a further larger, cross-center study in the future. Also, the study was retrospective in design which may have a potential bias regarding patient selection and limits the possibility of verifying data. The use of propensity score matching would have several limitations. Firstly, HCC with BDTT (Ueda classification II-IV) usually presents with obstructive jaundice and more than half of this group had pre-operative cholangitis which rarely presents in HCC without BDTT. Secondly, the significantly different factors between both groups which were associated with long term outcomes were inserted in the Cox-regression analysis but no significance association with long term survival, e.g., age, blood loss, blood transfusion and postoperative complications was found.

\section{Conclusions}

The results of this study indicate that HCC with macroscopic BDTT was not an end-stage condition. Tumor size $\geq 5 \mathrm{~cm}, \mathrm{AFP} \geq 200 \mathrm{ng} / \mathrm{dL}$ and resection margin were strong prognostic factors in the determination of long-term survival. On the other hand, presence of macroscopic BDTT did not have a statistically significant influence on recurrence free and overall survival after curative resection in selected patients. In patients who have preserved liver function, major liver resection with a selective bile duct 
preservation approach showed comparable long-term outcomes with a non-BDTT group and maintained options for treatment of recurrence in the future.

\section{Acknowledgments}

Funding: None.

\section{Footnote}

Reporting Checklist: The authors have completed the STROBE reporting checklist. Available at http://dx.doi. org/10.21037/hbsn.2019.10.26

Data Sharing Statement: Available at http://dx.doi. org/10.21037/hbsn.2019.10.26

Conflicts of Interest: All authors have completed the ICMJE uniform disclosure form (available at http://dx.doi. org/10.21037/hbsn.2019.10.26). The authors have no conflicts of interest to declare.

Ethical Statement: The authors are accountable for all aspects of the work in ensuring that questions related to the accuracy or integrity of any part of the work are appropriately investigated and resolved. All patients gave written consent for a review of their medical records. This study (Study code: Sur-2557-02473) was approved by the institutional review board of Chiang Mai University (Certificate of approval number 346/2014). The study was performed in accordance with the Declaration of Helsinki (as revised in 2013).

Open Access Statement: This is an Open Access article distributed in accordance with the Creative Commons Attribution-NonCommercial-NoDerivs 4.0 International License (CC BY-NC-ND 4.0), which permits the noncommercial replication and distribution of the article with the strict proviso that no changes or edits are made and the original work is properly cited (including links to both the formal publication through the relevant DOI and the license). See: https://creativecommons.org/licenses/by-nc-nd/4.0/.

\section{References}

1. Ferlay J, Soerjomataram I, Dikshit R, et al. Cancer incidence and mortality worldwide: sources, methods and major patterns in GLOBOCAN 2012. Int J Cancer
2015;136:E359-86.

2. Ferenci $P$, Fried $M$, Labrecque D, et al. Hepatocellular carcinoma (HCC): a global perspective. J Clin Gastroenterol 2010;44:239-45.

3. Moon DB, Hwang S, Wang HJ, et al. Surgical outcomes of hepatocellular carcinoma with bile duct tumor thrombus: a Korean multicenter study. World J Surg 2013;37:443-51.

4. Navadgi S, Chang CC, Bartlett A, et al. Systematic review and meta-analysis of outcomes after liver resection in patients with hepatocellular carcinoma (HCC) with and without bile duct thrombus. HPB (Oxford) 2016;18:312-6.

5. Yeh CN, Jan YY, Lee WC, et al. Hepatic resection for hepatocellular carcinoma with obstructive jaundice due to biliary tumor thrombi. World J Surg 2004;28:471-5.

6. Rammohan A, Sathyanesan J, Rajendran K, et al. Bile duct thrombi in hepatocellular carcinoma: is aggressive surgery worthwhile? HPB (Oxford) 2015;17:508-13.

7. Ueda M, Takeuchi T, Takayasu T, et al. Classification and surgical treatment of hepatocellular carcinoma (HCC) with bile duct thrombi. Hepatogastroenterology 1994;41:349-54.

8. Chotirosniramit A, Liwattanakun A, Lapisatepun W, et al. A single institution report of 19 hepatocellular carcinoma patients with bile duct tumor thrombus. J Hepatocell Carcinoma 2017;4:41-7.

9. Tangkijvanich P, Mahachai V, Komolmit P, et al. Hepatitis $\mathrm{B}$ virus genotypes and hepatocellular carcinoma in Thailand. World J Gastroenterol 2005;11:2238-43.

10. Orimo T, Kamiyama T, Yokoo H, et al. Hepatectomy for Hepatocellular Carcinoma with Bile Duct Tumor Thrombus, Including Cases with Obstructive Jaundice. Ann Surg Oncol 2016;23:2627-34.

11. Zeng H, Xu LB, Wen JM, et al. Hepatocellular carcinoma with bile duct tumor thrombus: a clinicopathological analysis of factors predictive of recurrence and outcome after surgery. Medicine (Baltimore) 2015;94:e364.

12. Oba A, Takahashi S, Kato Y, et al. Usefulness of resection for hepatocellular carcinoma with macroscopic bile duct tumor thrombus. Anticancer Res 2014;34:4367-72.

13. Shiomi M, Kamiya J, Nagino M, et al. Hepatocellular carcinoma with biliary tumor thrombi: aggressive operative approach after appropriate preoperative management. Surgery 2001;129:692-8.

14. Yamamoto S, Hasegawa K, Inoue Y, et al. Bile duct preserving surgery for hepatocellular carcinoma with bile duct tumor thrombus. Ann Surg 2015;261:e123-5.

15. Abe T, Kajiyama K, Harimoto N, et al. Intrahepatic bile duct recurrence of hepatocellular carcinoma without a 
detectable liver tumor. Int J Surg Case Rep 2012;3:275-8.

16. Peng SY, Wang JW, Liu YB, et al. Surgical intervention for obstructive jaundice due to biliary tumor thrombus in hepatocellular carcinoma. World J Surg 2004;28:43-6.

17. Kim DS, Kim BW, Hatano E, et al. Surgical Outcomes of Hepatocellular Carcinoma With Bile Duct Tumor Thrombus: A Korea-Japan Multicenter Study. Ann Surg 2020;271:913-21.

18. Hu XG, Mao W, Hong SY, et al. Surgical treatment for hepatocellular carcinoma with bile duct invasion. Ann Surg Treat Res 2016;90:139-46.

19. Wong TC, Cheung TT, Chok KS, et al. Outcomes of hepatectomy for hepatocellular carcinoma with bile duct tumour thrombus. HPB (Oxford) 2015;17:401-8.

20. Abdel-Rahman O. Assessment of the discriminating

Cite this article as: Chotirosniramit A, Liwattanakun A, Junrungsee S, Ko-iam W, Sandhu T, Lapisatepun W. The benefit of curative liver resection with a selective bile duct preserving approach for hepatocellular carcinoma with macroscopic bile duct tumor thrombus. HepatoBiliary Surg Nutr 2020;9(6):729-738. doi: $10.21037 / \mathrm{hbsn} .2019 .10 .26$ value of the 8th AJCC stage grouping for hepatocellular carcinoma. HPB (Oxford) 2018;20:41-8.

21. Wang C, Yang Y, Sun D, et al. Prognosis of hepatocellular carcinoma patients with bile duct tumor thrombus after hepatic resection or liver transplantation in Asian populations: A meta-analysis. PLoS One 2017;12:e0176827.

22. Hoffmann R, Rempp H, Schmidt D, et al. Prolonged antibiotic prophylaxis in patients with bilioenteric anastomosis undergoing percutaneous radiofrequency ablation. J Vasc Interv Radiol 2012;23:545-51.

23. Woo S, Chung JW, Hur S, et al. Liver abscess after transarterial chemoembolization in patients with bilioenteric anastomosis: frequency and risk factors. AJR Am J Roentgenol 2013;200:1370-7. 